\title{
LA DEFENSA DEL DERECHO AL AGUA COMO DERECHO COLECTIVO DESDE SU PERSPECTIVA AMBIENTAL. LA CAUSA "KERSICH, JUAN GABRIEL Y OTROS C. AGUAS BONAERENSES Y OTROS S/ AMPARO”
}

\author{
ELISA PÉREZ DE LOS CoBOS HERNÁNDEZ \\ Profesora de la Universidad de Murcia \\ Abogada \\ eperezdeloscobos@um.es
}

Recibido: 26 de mayo de 2015 / Aceptado: 29 de junio de 2015

RESUMEN: La reforma constitucional de 1994 otorgó rango constitucional a los tratados internacionales de derechos humanos, incorporando el derecho al agua al ordenamiento jurídico argentino. El reciente fallo de la Corte Suprema de Justicia de la Nación de 2 de diciembre de 2014, dictado en los autos Kersich, sirve para comprobar la protección que se brinda al acceso al agua potable y el tipo de proceso más eficiente para hacer efectivo este derecho en Argentina.

RESUM: La reforma constitucional de 1994 va atorgar rang constitucional als tractats internacionals de drets humans, tot incorporant el dret a l'aigua a l'ordenament jurídic argentí. El pronunciament recent del Tribunal Suprem de Justícia de la Nació, de 2 de desembre de 2014, dictat arran de les actuacions Kersich, serveix per comprovar la protección que es concedeix a l'accés a l'aigua potable i el tipus de procés més eficient per fer efectiu aquest dret a l'Argentina.

ABSTRACT: The constitutional reform of 1994 gave constitutional status to the
international human rights treaties, incorporating the right to water to 0 the Argentine
legal system. The recent judgment of the Supreme Court of Justice of the Nation, in the 
Kersich case, is used to check the protection of access to safe drinking water and the type of more efficient process to ensure the effective exercise of this right in Argentina.

PALABRAS CLAVE: Agua - Argentina - Derechos humanos - Procedimiento judicial.

PARAULES CLAU: Aigua - Argentina — Drets humans — Procediment judicial

KEYWORDS: Water - Argentina - Human rights - judicial process.

SUMARIO: I. Introducción: el derecho a un medio ambiente sano y el derecho al agua como derechos de incidencia colectiva. II. El reconocimiento del derecho humano al agua como categoría autónoma y su incorporación al ordenamiento jurídico argentino. III. La causa "Kersich, Juan Gabriel y otros c/ Aguas Bonaerenses y otros s/ amparo" y la protección del derecho al agua potable. 1. Antecedentes: planteamiento del conflicto y desarrollo procesal de las actuaciones. 2. Doctrina de la Corte Suprema de Justicia de la Nación. IV. Conclusiones. V. Bibliografía.

\section{INTRODUCCIÓN: EL DERECHO A UN MEDIO AMBIENTE SANO Y EL DERECHO AL AGUA COMO DERECHOS DE INCIDENCIA COLECTIVA}

El reconocimiento de los derechos a un medio ambiente sano y al agua se consolida a nivel internacional a través de los denominados derechos de tercera generación ${ }^{1}$. Estos, a diferencia de las generaciones anteriores, presentan un sujeto colectivo - la humanidad en su conjunto- y tienen por objeto bienes jurídicos que pertenecen al género humano, tanto a las generaciones presentes como a las futuras. Este aspecto es lo que MARTÍN MATEO denomina "deberes intergeneracionales" para subsanar la ausencia "en nuestro código genético" de "un mandato de ayuda solidaria que vaya más allá de la propia familia"2. Estamos ante derechos públicos subjetivos caracterizados por

\footnotetext{
${ }^{1}$ Cfr. GÓMEZ GARCÍA, J. A., Los llamados derechos humanos de tercera generación, Muinelo Cobo, J. C. y Muñoz de Baena Simón, J. L. (coords.), Filosofía del Derecho, UNED, Madrid, 2014, pp. 232 y ss.

${ }^{2}$ MARTÍN MATEO, R., El hombre, una especie en peligro, Campomanes, Madrid, 1993, pp. 96-97.
} 
su supraindividualidad y por la homogeneidad cualitativa del contenido de las pretensiones que se ejercitan ${ }^{3}$.

Sin embargo, pese a su importancia, algunos autores los han calificado de soft rights o derechos blandos por su escaso reconocimiento constitucional ${ }^{4}$. En el caso de Argentina, la reforma constitucional de 1994 profundizó en la filosofía humanista y personalista de la Constitución Nacional $(\mathrm{CN})$, que hace de los derechos humanos su objeto más importante ${ }^{5}$. Se incorpora a la Norma Suprema el reconocimiento de nuevos derechos y garantías para los ciudadanos, junto con el otorgamiento de rango constitucional a los tratados internacionales de derechos humanos (ex artículo 75 inc. 22 $\mathrm{CN})^{6}$. La Constitución ha dado entrada a los referidos derechos de tercera generación o

\footnotetext{
${ }^{3}$ En este sentido, QUIROGA LAVIÉ, BENEDETTI Y CENICACELAYA ponen de manifiesto que "no están en la cabeza de un sujeto determinado, sino esparcidos entre todos lo que conforman una comunidad o parte de ella (una fracción), que no se encuentran vinculados entre sí por un nexo previamente establecido. Aunque no haya un perjuicio personal y directo, cada uno de los miembros de esta pluralidad tiene una suerte de parte indivisa que lo habilita o legitima para reclamar en nombre propio y en el de todos los demás". QUIROGA LAVIÉ, H., BENEDETTI, M. A. y CENICACELAYA, M., Derecho Constitucional Argentino, T. I, Rubinzal-Culzoni, Buenos Aires, 2001, pp. 292-293.
}

${ }^{4}$ AgUilar ROJAS, G. e IZA, A. (eds.), Derecho ambiental en Centro América, T. I, UICN, Gland, Suiza, 2009, pp. 20 y ss.

${ }^{5}$ En este sentido, ANDORNO, L. O., "Aspectos constitucionales de la protección del medio ambiente", $J A$, T. IV, 1998; WALSH, J. R., "El medio ambiente en la nueva Constitución argentina", $L L$, Supl. de Derecho Ambiental, núm. 1, 1994; GAMBIER, B. y LAGO, D. H., "El medio ambiente y su reciente recepción constitucional”, ED, T. 163, 1995; ANTÚNEZ SÁNCHEZ, A. y BRUZÓN VILTRES, C., "Una mirada a los Derechos Humanos desde la óptica del Derecho Ambiental Internacional. Resultados de la primera década del siglo XXI", Revista de Derecho Ambiental, núm. 34, Buenos Aires, 2013.

${ }^{6} \mathrm{El}$ artículo 75 inc. $22 \mathrm{CN}$ reconoce jerarquía constitucional, en las condiciones de su vigencia, a los siguientes tratados: Declaración Americana de los Derechos y Deberes del Hombre, aprobada en la IX Conferencia Internacional Americana, Bogotá, Colombia, 1948; Declaración Universal de Derechos Humanos, adoptada por la AGNU mediante Resolución núm. 217 A (III), el 10 de diciembre de 1948, en París; Convención Americana sobre Derechos Humanos (también llamada Pacto de San José de Costa Rica o CADH), suscrita tras la Conferencia Especializada Interamericana de Derechos Humanos, el 22 de noviembre de 1969, en la ciudad de San José, Costa Rica, que entraría en vigor el 18 de julio de 1978; Pacto Internacional de Derechos Económicos, Sociales y Culturales (ICESCR), adoptado por la AGNU mediante la Resolución núm. 2200A (XXI), de 16 de diciembre de 1966; Pacto Internacional de Derechos Civiles y Políticos y su Protocolo Facultativo, adoptado por AGNU el 16 de diciembre de 1996; Convención sobre la Prevención y la Sanción del Delito de Genocidio, aprobada por las Naciones Unidas en 1948; Convención Internacional sobre la Eliminación de todas las Formas de Discriminación Racial, realizada por la ONU y proclamada por la AGNU el 20 de noviembre de 1963; Convención sobre la Eliminación de todas las Formas de Discriminación contra la Mujer, aprobada por la AGNU el 18 de diciembre de 1979, fruto del trabajo realizado por la Comisión de la Condición Jurídica y Social de la Mujer, creada en 1946 por la ONU; Convención contra la Tortura y otros Tratos o Penas Crueles, Inhumanos o Degradantes, adoptada por la AGNU el 10 de diciembre de 1984; y la Convención sobre los Derechos del Niño, adoptada y abierta a la firma y ratificación por la AGNU en su resolución núm. 44/25, de 20 de noviembre de 1989. El precepto especifica que estos tratados, "en las condiciones de su vigencia, tienen jerarquía constitucional, no derogan artículo alguno de la primera parte de esta Constitución y deben entenderse complementarios de los derechos y garantías por ella reconocidos. Sólo podrán ser denunciados, en su caso, por el Poder Ejecutivo Nacional, previa aprobación de las dos terceras partes de la totalidad de los miembros de cada Cámara". 
derechos de incidencia colectiva en los artículos 41 y $42 \mathrm{CN}^{7}$, que engloban como género los derechos ambientales según los términos del propio artículo $43 \mathrm{CN}^{8}$.

Para la defensa y garantías de estos derechos colectivos, la reforma de la Constitución argentina de 1994 introdujo, junto con el reconocimiento del amparo constitucional clásico, una referencia expresa al amparo colectivo, consolidando con ello lo que ya era una práctica jurisprudencial ${ }^{9}$. El artículo 43.2 CN dispone expresamente que "podrán interponer esta acción contra cualquier forma de discriminación y en lo relativo a los derechos que protegen al ambiente, a la competencia, al usuario y al consumidor, así como a los derechos de incidencia colectiva en general, el afectado, el defensor del pueblo y las asociaciones que propendan a esos fines, registradas conforme a la ley, la que determinará los requisitos y formas de su organización”.

Se trata de una garantía constitucional derivada de la acción de amparo individual de la que se conservan los elementos centrales ${ }^{10}$. Si bien el amparo colectivo presenta características propias que le aportan un mayor espectro: i) los derechos que se vulneran son derechos de incidencia colectiva — como lo es el medio ambiente-; ii) el sujeto legitimado para promover el amparo, es decir, aquel que sin ser titular de un derecho subjetivo se encuentra vinculado al colectivo sobre el que incide la vulneración, puede ser cualquier persona afectada, cualquier asociación vinculada o el Defensor del Pueblo;

\footnotetext{
${ }^{7}$ Artículo $41 \mathrm{CN}$ : "Todos los habitantes gozan del derecho a un ambiente sano, equilibrado, apto para el desarrollo humano y para que las actividades productivas satisfagan las necesidades presentes sin comprometer las de las generaciones futuras; y tienen el deber de preservarlo"; Artículo 42 CN: "Los consumidores y usuarios de bienes y servicios tienen derecho, en la relación de consumo, a la protección de su salud, seguridad e intereses económicos; a una información adecuada y veraz; a la libertad de elección, y a condiciones de trato equitativo y digno".

${ }^{8}$ Artículo $43 \mathrm{CN}$ : “[...] toda persona puede interponer acción expedita y rápida de amparo, [...] podrán interponer esta acción contra cualquier forma de discriminación y en lo relativo a los derechos que protegen al ambiente, a la competencia, al usuario y al consumidor, así como a los derechos de incidencia colectiva en general $[\ldots]$ ".

${ }^{9}$ Vid. Sentencia de la Cámara Nacional Civil, sala D, de 22 de agosto de 1990, dictada en la causa "Quesada, Ricardo c/ Municipalidad de la Ciudad de Buenos Aires"; Sentencia del Juzgado Federal Contencioso-Administrativo de Primera Instancia núm. 2, de 10 de mayo de 1983, "Kattan c/ Gobierno Nacional", popularmente conocida como la "caza de toninas"; Sentencia de la Cámara Nacional Contencioso-Administrativa Federal, sala III, de 8 de agosto de 1994, "Schroder, Juan c/ Estado Nacional"; o Sentencia de la Cámara $1^{\mathrm{a}}$ en lo Civil y Comercial de La Plata, sala III, de 15 de noviembre de 1994, "Sagarduy, Alberto".

${ }^{10}$ Entre estos elementos comunes: el carácter sumarísimo del procedimiento; el carácter del transgresor, que puede ser público o privado y puede manifestarse a través de un hacer (acto) o de un no hacer (omisión); y la caracterización de la transgresión: que con arbitrariedad o ilegitimidad manifiesta lesione, altere, restrinja o amenace, en forma actual o inminente. Cfr. ÁLVAREZ, N. R. (2006, 8 de septiembre). Derechos de Incidencia Colectiva y Amparo. Recuperado el 22 de septiembre de 2015, de http://www.poderyderecho.blogspot.com.ar/2006/09/derechos-de-incidencia-colectiva-y.html .
} 
y iii) la sentencia que se dicte, en caso de declarar procedente el reclamo, tiene efectos erga omnes, estableciendo una conducta de carácter general más allá de las partes del proceso. La importancia de estos intereses difusos se plasma también a nivel procesal, configurando un procedimiento judicial de características singulares que han dado pie a fallos históricos como el dictado en la causa "Mendoza, Beatriz S. y otros v. Estado Nacional y otros s/daños y perjuicios (daños derivados de la contaminación ambiental del Río Matanza Riachuelo)"11. Como señala VALLS, la causa "Mendoza" proporciona "una valiosa experiencia para inspirar un proceso típicamente ambiental"12.

Todas estas características resultan igualmente predicables respecto del derecho al agua. Como señala la Corte Suprema de Justicia de la Nación (CSJN), "en el campo de los derechos de incidencia colectiva, es fundamental la protección del agua para que la naturaleza mantenga su funcionamiento como sistema y su capacidad de resiliencia"13. No existe hoy ningún género de duda sobre la interrelación entre el agua y el medio ambiente. Es evidente que los problemas medioambientales, en especial la contaminación, tienen una fuerte influencia sobre la implementación de todos los derechos humanos, resultando especialmente crítico su impacto sobre el derecho humano al agua y al saneamiento. Así pues, nos encontramos, en pleno siglo XXI, con dos desafíos fundamentales: por una parte, la necesidad de garantizar el acceso universal al agua potable y al saneamiento, y, por otra, la obligada protección y conservación del medio ambiente.

\footnotetext{
${ }^{11}$ SCJN, de 8 de julio de 2008, fallos 331:1622, "Mendoza, Beatriz S. y otros v. Estado Nacional y otros s/daños y perjuicios (daños derivados de la contaminación ambiental del Río Matanza Riachuelo)". Sobre esta causa, vid. PÉREZ DE LOS COBOS HERNÁNDEZ, E., "Leading case ambiental: la causa "Mendoza" y el reconocimiento de los derechos de tercera generación", Revista Aranzadi de Derecho Ambiental, núm. 30, enero-abril 2015, pp. 383 - 437.

${ }^{12}$ VALLS señala que "para tramitar esta causa la Corte diseñó de oficio un proceso ad hoc que provee una valiosa experiencia para inspirar un proceso típicamente ambiental. Es cierto que no hay dos casos iguales, pero la estructura del litigio ambiental es universal". VALLS, M. F., "La Corte Suprema de Justicia de la Nación marca pautas sobre su criterio en materia ambiental", Equipo Federal de Trabajo, sección Jurisprudencia Corte Suprema, núm. 45, 2009.

${ }^{13}$ Cfr. SCSJN de 2 de diciembre de 2014, K.42.XLIX, "Kersich, Juan Gabriel y otros c/ Aguas Bonaerenses y otros s/ amparo", Consid. $12^{\circ}$.
} 


\section{EL RECONOCIMIENTO DEL DERECHO HUMANO AL AGUA COMO CATEGORÍA AUTÓNOMA Y SU INCORPORACIÓN AL ORDENAMIENTO JURÍDICO ARGENTINO}

La reforma constitucional de 1994 consagró la apertura del ordenamiento jurídico argentino hacia el derecho internacional de los derechos humanos. A través del artículo 75 inc. $22 \mathrm{CN}$ se otorga rango constitucional a los tratados internacionales de derechos humanos, reconociéndose, además, la posibilidad de otorgar igual jerarquía, en el futuro, a otros tratados y convenciones de naturaleza similar ${ }^{14}$. De este modo, si bien el derecho al agua no queda expresamente recogido entre los derechos fundamentales amparados por la Norma Suprema, su integración en el orden interno resulta incuestionable. El derecho internacional ha establecido que la legislación nacional debe ser acorde con los tratados de derechos humanos en los que Argentina es parte.

Por ello, analizamos en primer lugar, si bien de forma sucinta, el derecho humano al agua en el marco del derecho supranacional. Un marco en el que destacan dos hitos fundamentales como la Resolución de la Asamblea General de la Naciones Unidas (AGNU) de 28 de julio de 2010 y la Resolución del Consejo de Derechos Humanos de la ONU de 30 de septiembre de $2010^{15}$. El 28 de julio de 2010, la AGNU adoptó una resolución que, pese a no tener carácter vinculante, deviene histórica. En ella se reconoce que "el derecho al agua potable y el saneamiento es un derecho humano esencial para el pleno disfrute de la vida y de todos los derechos humanos”. Dos meses más tarde, el 30 de septiembre de 2010, el Consejo de Derechos Humanos de la ONU adoptó una segunda resolución por la que se afirma que "el derecho humano al agua potable y el saneamiento deriva del derecho a un nivel de vida adecuado y está indisolublemente asociado al derecho al más alto nivel posible de salud física y mental, así como al derecho a la vida y la dignidad humana". El Consejo de Derechos Humanos va un paso más allá que la AGNU y reconoce que este derecho implica obligaciones jurídicas vinculantes. Afirma que "el derecho al agua y al saneamiento es un derecho humano, igual al resto de derechos humanos lo que implica que es justiciable y de

\footnotetext{
${ }^{14}$ Junto con el reconocimiento de jerarquía constitucional a los tratados internacionales de derechos humanos ya examinados, el artículo 75 inc. 22, in fine, señala que "los demás tratados y convenciones sobre derechos humanos, luego de ser aprobados por el Congreso, requerirán del voto de las dos terceras partes de la totalidad de los miembros de cada Cámara para gozar de la jerarquía constitucional”.

${ }^{15}$ Resolución núm. 64/292 de la AGNU, de 28 de julio de 2010, (A/RES/64/292), sexagésimo cuarto período de sesiones, tema 48 del programa y Resolución del Consejo de Derechos Humanos de la ONU, de 30 de septiembre de 2010, (A/HRC/RES/15/9), $15 .^{\circ}$ período de sesiones, Tema 3 de la agenda.
} 
aplicación obligatoria". Además, este derecho se incluye en dos tratados internacionales vigentes como el PIDESC y la Convención sobre los Derechos del Niño, a los que la $\mathrm{CN}$ le ha reconocido expresa jerarquía constitucional.

En cualquier caso, no se observan aquí todas las exigencias que recoge el derecho internacional. Los Estados deben actuar dando debido cumplimiento a las obligaciones que se contemplan en la Observación General núm. 15 del Comité de las Naciones Unidas de Derechos Económicos, Sociales y Culturales, de noviembre de $2002^{16}$. Además, deben tenerse en cuenta los compromisos contraídos por la comunidad internacional de cumplir plenamente los Objetivos de Desarrollo del Milenio, destacando, en ese contexto, la determinación de los jefes de Estado y de Gobierno, expresada en la Declaración del Milenio, de reducir a la mitad para 2015 la proporción de personas que no tienen acceso al agua potable o que no pueden pagarla y la proporción de personas que no tienen acceso a servicios básicos de saneamiento, de conformidad con lo acordado en el Plan de Aplicación de las Decisiones de la Cumbre Mundial sobre el Desarrollo Sostenible (Plan de Aplicación de las Decisiones de Johannesburgo) ${ }^{17}$. Son numerosos, pues, los instrumentos internacionales que informan el derecho al agua en el ordenamiento jurídico nacional.

El reconocimiento internacional del derecho humano al agua no significa que su efectividad deje fuera a las instancias nacionales. Debe tenerse en cuenta el reconocimiento de este derecho fundamental que se lleva a cabo a nivel normativo, doctrinal y jurisprudencial en Argentina. A nivel normativo destaca el Acuerdo Federal del Agua, de 17 de septiembre de 2003, a través del cual fueron acordados los Principios Rectores de la Política Hídrica de la República Argentina (PRPH) ${ }^{18}$. Estos

\footnotetext{
${ }^{16}$ La Observación General núm. 15 del Comité de las Naciones Unidas de Derechos Económicos, Sociales y Culturales incluye el derecho al agua dentro del campo de los derechos humanos a la salud, al nivel de vida y a la alimentación, de conformidad con el PIDESC. De acuerdo con su artículo I.1., "el derecho humano al agua es indispensable para una vida humana digna". La Observación núm. 15 también define el derecho al agua como "el derecho de cada uno a disponer de agua suficiente, saludable, aceptable, físicamente accesible y asequible para su uso personal y doméstico". Observación General núm. 15. "El derecho al agua" (arts. 11 y 12 del PIDESC), Comité de las Naciones Unidas de Derechos Económicos, Sociales y Culturales. Noviembre de 2002.

${ }^{17}$ Reunión Plenaria de Alto Nivel de la AGNU, de 19 de octubre de 2010, A/RES/65/1, sexagésimo quinto período de sesiones sobre los Objetivos de Desarrollo del Milenio, titulado "Cumplir la promesa: unidos para lograr los Objetivos de Desarrollo del Milenio".

${ }^{18}$ El Acuerdo Federal del Agua, de 17 de septiembre de 2003, por el que se acuerdan los Principios Rectores de la Política Hídrica de la República Argentina, se firmó por los representantes de la Nación, de las Provincias y de la Ciudad Autónoma de Buenos Aires, elevándose al Congreso de la Nación para materializar una normativa a través de la Ley Marco Nacional de Política Hídrica. Pese a no haber sido aún normativizados, constituyen una suerte de derecho blando — soft law - aceptado en la mayoría de las
} 
tienen por objeto brindar lineamientos que permitan la integración de aspectos técnicos, sociales, económicos, legales, institucionales y ambientales del agua en una gestión moderna, armónica y sustentable de los recursos hídricos. Resultan de obligada mención los PRPH referidos al principio de unidad de gestión de la cuenca hidrográfica, el dominio público del agua o el derecho al agua como un derecho humano básico. Hallamos otros reconocimientos normativos a nivel nacional en la protección penal brindada al tipificar como delito contra la salud pública el envenenar o adulterar aguas potables ex artículo 200 del Código Penal ${ }^{19}$. A nivel de las provincias, también se lleva a cabo el reconocimiento constitucional e infraconstitucional en los códigos y leyes de $\operatorname{aguas}^{20}$.

Por su parte, la doctrina y la jurisprudencia argentina se han referido en reiteradas ocasiones al derecho humano al agua. Autores como SMETS, MARTÍN, PINTO, TORCHIA, AGILAR, IZA, GONZÁLEZ DEL SOLAR, RUIZ FRITES, HITTERS o FAPPIANO se han ocupado detenidamente de su estudio ${ }^{21}$. A nivel jurisprudencial destacan pronunciamientos como el de la Cámara de Apelaciones en lo ContenciosoAdministrativo de Mar del Plata, de 8 de octubre de 2013, dictado en la causa "Johnston, Juan Alberto y otros c. Aguas Bonaerenses Sociedad Anónima (ABSA) s/

jurisdicciones e informan el derecho de aguas argentino. Cfr. IZA, A. y ROVERE, M. B., Gobernanza del agua en América del Sur: dimensión ambiental, UICN, Gland, Suiza, y Cambridge, Reino Unido, 2006; CAVALLI, A., Derecho de aguas, Documento de trabajo núm. 168, Departamento de Investigaciones de la Universidad de Belgrano, Buenos Aires, 2007.

${ }^{19}$ Artículo 200 CP, Ley núm. 11.179 (T.O. 1984 actualizado): “[...] será reprimido con reclusión o prisión de tres a diez años y multa de diez mil a doscientos mil pesos, el que envenenare, adulterare o falsificare de un modo peligroso para la salud, aguas potables o sustancias alimenticias o medicinales destinadas al uso público o al consumo de una colectividad de personas".

${ }^{20}$ Sirva de ejemplo la Constitución de Corrientes (2007), cuyo artículo 59 dispone que "el agua es un bien social para la vida. El estado provincial debe garantizar el acceso al agua saludable y la existencia de control y cogestión social a través del mecanismo que establece la Ley". Por su parte, a nivel infraconstitucional, la Ley 3295, de Gestión Ambiental del Agua de la Ciudad Autónoma de Buenos Aires, dispone en su artículo 3 que "garantiza a todos sus habitantes el acceso al agua potable en cantidad y calidad suficiente para usos personales y domésticos como derecho humano fundamental". Cfr. PÉREZ DE LOS COBOS HERNÁNDEZ, E., La incorporación de la variable ambiental a los conflictos competenciales en materia de aguas en España y en Argentina, tesis doctoral, Universidad de Murcia, España, 2014.

${ }^{21}$ SMETS, H., El derecho al agua en las legislaciones nacionales, Universidad de Rosario, Bogotá, 2006; MARTÍN, L. y PINTO, M., Origen, evolución y estado actual del derecho al agua en América Latina, revista Bioderecho.es, vol. 1, núm. 1, 2014, pp. 123-176; MARTÍN, L., PINTO, M. y TORCHIA, N., El Derecho Humano al agua. Particularidades de su reconocimiento, evolución y ejercicio, Abeledo Perrot, Buenos Aires, 2008; AGUILAR e IZA (eds.), Derecho... cit.; MARTÍN, L., PINTO, M., TORCHIA, N., GONZÁLEZ DEL SOLAR, N., y RUIZ FRITES, S., "Configuración del derecho humano al agua: del uso común al derecho humano. Particularidades de su integración y expansión conceptual”, Embid Irujo, A. (dir.), El derecho al agua, Thomson Aranzadi, Cizur Menor, 2006, pp. 285-316; HITTERS, J. C. y FAPPIANO, O. L., Derecho internacional de los Derechos Humanos, t. II, vol. 2, Ediar, Buenos Aires, 2007. 
amparo". Se parte aquí del rechazo por el juez a quo de la acción de amparo interpuesta por los actores frente a un inminente corte de servicio de agua potable. Apelada la Sentencia, la Cámara hizo lugar al recurso incluyendo entre sus razonamientos el derecho al agua como un derecho humano fundamental reconocido en la cúspide del ordenamiento jurídico argentino ex artículo 75 inc. 22 CN. El juez Riccitelli expuso con una claridad meridiana que "no puede pasar inadvertido que en el sub lite se encuentra comprometido derecho al acceso al agua potable como derecho humano fundamental, reconocido en la cúspide misma de nuestro derecho positivo (arts. 75 inc. 22, Constitución nacional; 11 y 12 del Pacto Internacional de Derecho Económicos, Sociales y Culturales) y definido como el derecho de todos a disponer de una cantidad suficiente de agua salubre, aceptable, físicamente accesible y asequible para uso personal y doméstico (párr. 2 de la O.G. 15). Por ello, teniendo presente que el amparo es un proceso utilizable en las delicadas y extremas situaciones en las que, por carecer de otras vías idóneas o aptas, existe un peligro actual o potencial de la protección de derechos fundamentales y tratándose en el caso de salvaguardar uno con estrecha vinculación con la protección de la vida y la salud de los habitantes, la vía elegida no resulta irrazonable",22.

Asimismo, la Sentencia de la Cámara de Apelaciones en lo Civil y Comercial de Corrientes, sala IV, de 19 de junio de 2013, dictada en la causa "Gallo, Nelson Carlos c. Aguas de Corrientes S.A. s/amparo”. La Cámara, resolviendo la acción de amparo promovida por el beneficiario de un sistema de utilización del servicio de agua potable con carácter "social" a fin de que se prohibiera a la empresa prestataria cortarle el suministro, hace un expreso reconocimiento del derecho humano al agua en el constitucionalismo provincial, señalando que "no caben dudas que el derecho al acceso al agua potable como derecho humano se halla consagrado en nuestra Carta Magna Provincial es por ende un derecho fundamental y así lo enumeraron expresamente nuestros constituyentes provinciales al reformar nuestra Constitución Provincial en 2007, estableciendo en el art. 59 que 'el agua es un bien social esencial para la vida. El Estado Provincial debe garantizar el acceso al agua saludable'. Al ser derecho humano

\footnotetext{
${ }^{22}$ Sentencia de la Cámara de Apelaciones en lo Contencioso-Administrativo de Mar del Plata, de 8 de octubre de 2013, dictada en la causa "Johnston, Juan Alberto y otros c. Aguas Bonaerenses Sociedad Anónima (ABSA) s/ amparo", fallo particular del juez Riccitelli.
} 
fundamental, nos encontramos en la cúspide misma de nuestro derecho positivo" ${ }^{23}$.

En cualquier caso, la Corte Suprema ya se había pronunciado al respecto en un momento anterior, recordando por todas la Sentencia de 18 de septiembre de 2007, dictada en la causa "Defensor del Pueblo de la Nación c. Estado Nacional y otra". En este caso, el Defensor del Pueblo de la Nación dedujo acción de amparo contra la Provincia del Chaco y el Estado Nacional a fin de que se adoptaran las medidas necesarias para modificar la condición actual de vida de los habitantes de la región sudeste del Departamento General Güemes y noroeste del Departamento Libertador General San Martín de ese estado local, en su gran mayoría de la etnia toba, quienes, según mantuvo la Corte, se encontraban en una situación de emergencia extrema. A su vez, solicitó que, con carácter cautelar, se ordenase a los demandados la realización de las acciones adecuadas para cubrir sus necesidades básicas. La CSJN hizo lugar a la medida cautelar ordenando a la Nación y a la provincia de Chaco el suministro de agua potable y alimentos a las comunidades indígenas.

A la luz de lo anterior, puede afirmarse que la problemática del derecho humano al agua no se halla tanto en su reconocimiento positivo, doctrinal o jurisprudencial como en la determinación de su contenido. El derecho al agua presenta un espectro muy superior al decimonónico uso común e incluso más amplio que la mera noción del servicio público de abastecimiento poblacional ${ }^{24}$. Debe tenerse en cuenta que, tal y como concreta la Observación General núm. 15 del Comité de Derechos Económicos, Sociales y Culturales del Consejo Económico y Social de las Naciones Unidas de 2002, “el derecho humano al agua es el derecho de todos a disponer de agua suficiente, salubre, aceptable, accesible y asequible para el uso personal y doméstico" 25 . De acuerdo con lo anterior, el derecho humano al agua abarcaría solamente los usos personales y domésticos, es decir, el consumo, el lavado de ropa, la preparación de alimentos y la

\footnotetext{
${ }^{23}$ Sentencia de la Cámara de Apelaciones en lo Civil y Comercial de Corrientes, sala IV, de 19 de junio de 2013, causa "Gallo, Nelson Carlos c. Aguas de Corrientes S.A. s/amparo", apartado 6 del voto del juez Rodríguez. En el mismo sentido, las sentencias de la Cámara de Apelaciones en lo Civil y Comercial de Corrientes, sala IV, de 9 de noviembre de 2012, dictada en la causa "Romero, Andrea Cecilia y Núñez de Romero, Mónica I. c. Aguas de Corrientes S.A.”, y la Sentencia de la Cámara de Apelaciones en lo Contencioso-Administrativo de Tucumán, sala I, de 25 de febrero de 2010, dictada en la causa "Ramos, Elsa Mirta c. Sociedad Aguas del Tucumán”.

${ }^{24}$ Sentencia de la Cámara de Apelaciones en lo Civil y Comercial de Corrientes, sala IV, de 19 de junio de 2013, causa "Gallo, Nelson Carlos c. Aguas de Corrientes S.A. s/amparo", apartado 6.

${ }^{25}$ Observación General núm. 15. "El derecho al agua" (arts. 11 y 12 del PIDESC), Comité de las Naciones Unidas de Derechos Económicos, Sociales y Culturales. Noviembre de 2002.
} 
higiene personal y doméstica ${ }^{26}$. Sin embargo, el referido documento del Comité vincula, además, el derecho al agua con el derecho al más alto nivel posible de salud ${ }^{27}$ y con el derecho a una vivienda y una alimentación adecuadas ${ }^{28}$, declarando que debe darse prioridad "a los recursos hídricos necesarios para evitar el hambre y las enfermedades, así como para cumplir las obligaciones fundamentales que entraña cada uno de los derechos del Pacto" 29 .

Asimismo, el derecho humano al agua debe ser considerado conjuntamente con otros derechos consagrados en la Carta Internacional de Derechos Humanos, entre los que ocupa un lugar primordial el derecho a la vida y a la dignidad humana, vinculación que no hace sino ampliar el espectro del derecho de aguas. Nos hallamos ante un concepto que supera claramente la limitación a la satisfacción de las necesidades esenciales de subsistencia, comprendiendo, además, el agua necesaria para satisfacer otras necesidades como requisito previo para asegurar el ejercicio de otros derechos humanos ${ }^{30}$.

No existe, por lo tanto, duda alguna del reconocimiento interno del derecho al agua.

\footnotetext{
${ }^{26}$ OFICINA DEL ALTO COMISIONADO DE LAS NACIONES UNIDAS PARA LOS DERECHOS HUMANOS DE GINEBRA, "El derecho al agua", Folleto informativo núm. 35, p. 12.

${ }^{27}$ Artículo 12 del PIDESC de 1966, recogido asimismo en la Observación General núm. 14, del año 2000, del mismo Comité de Derechos.
}

${ }^{28}$ Artículo 11 del PIDESC y Observación General núm. 4, de 1991, del mismo Comité de Derechos.

${ }^{29}$ Observación General núm. 15, "El derecho al agua", artículos 11 y 12 del Pacto Internacional de Derechos Económicos, Sociales y Culturales, 29. ${ }^{\circ}$ período de sesiones, cit. De lo expuesto supra debe deducirse, dada la interdependencia y la indivisibilidad de todos los derechos humanos, que el derecho al agua asigna prioridad al uso de agua para la agricultura y el pastoreo cuando ello sea necesario para prevenir el hambre. Cfr. OFICINA DEL ALTO COMISIONADO DE LAS NACIONES UNIDAS PARA LOS DERECHOS HUMANOS DE GINEBRA, El derecho... cit., p. 13. En tal sentido, HITTERS Y FAPPIANO mantienen que "el acceso a suficiente agua limpia y a saneamiento es esencial para la efectividad del derecho a la salud, a la alimentación y a un sustento seguro (por ejemplo, en la producción de alimentos). Se ha interpretado recientemente que el derecho al agua, al igual que el derecho a los alimentos, ha de garantizar una disponibilidad, acceso (tanto físico como económico) y calidad (libre de organismos perjudiciales o contaminación) suficientes. Tal como ocurre con otros derechos económicos, sociales y culturales, debería concederse prioridad a las personas más vulnerables, es decir 'a las personas y grupos de personas que tradicionalmente han tenido dificultades para ejercer este derecho, en particular las mujeres, los niños, los grupos minoritarios' expresa la Observación General núm. 15 del Comité de Derechos Económicos, Sociales y Culturales". HITTERS Y FAPPIANO, Derecho... cit., pp. 1314 -1315.

${ }^{30}$ De acuerdo con PINTO y MARTÍN, "la vinculación del agua con la calidad de vida y con la satisfacción de otros derechos humanos es posiblemente la base de una expansión conceptual del derecho al agua que hoy se está produciendo, generándose un planteo superador de la concepción que vincula tal prerrogativa humana a las necesidades vitales de subsistencia que amparaba el uso común: este paradigma implica mucho más que la manutención, y exige no sólo una actividad planificadora sobre el mejor beneficio social al que se debe destinar el agua disponible, sino también en algunas circunstancias el otorgamiento de concesiones de uso especial que resulten una condición necesaria para la calidad de vida de los individuos". PINTO, M. y MARTÍN, L., "El Derecho Humano al Agua. Evolución, protección y efectividad", HYDRIA, año 8, núm. 39, 2012, p. 10. 
Bien como un derecho autónomo, bien como un presupuesto esencial para la realización de otros derechos, el derecho al agua resulta fundamental. Tampoco existe duda de su carácter individual y colectivo, siendo en esta última condición, como derecho colectivo, que deba ser analizada su protección a través del amparo previsto en el artículo $43 \mathrm{CN}$.

\section{LA CAUSA "KERSICH, JUAN GABRIEL Y OTROS C/ AGUAS BONAERENSES Y OTROS S/ AMPARO" Y LA PROTECCIÓN DEL DERECHO AL AGUA POTABLE}

Cuando una agresión al medio ambiente llega a ser de tal magnitud que el disfrute del derecho a la salud y/o el derecho a la vida misma se ven cuestionados, puede concluirse que el derecho a un medio ambiente adecuado constituye un derecho fundamental subjetivo vinculado al derecho a la vida ${ }^{31}$. Esta afirmación puede efectuarse en idénticos términos respecto del derecho al agua, donde la cantidad y calidad del recurso, gravemente erosionadas por la falta de medidas anteriores, ponen hoy en jaque los referidos derechos a la salud y a la vida.

La defensa de estos derechos reviste cada vez mayor importancia. En lo jurisdiccional se advierte una marcada expansión y multiplicación de procesos colectivos ambientales que permite a la CSJN configurar una jurisprudencia de avanzada en estos temas. En este sentido, reviste especial interés la reciente SCSJN de 2 de diciembre de 2014, dictada en los autos "Kersich, Juan Gabriel y otros c/ Aguas Bonaerenses y otros s/ amparo" (en adelante, "Kersich") ${ }^{32}$. Un pronunciamiento en el que el Alto Tribunal lleva a cabo un reconocimiento explícito de la condición del derecho al agua como un derecho colectivo derivado de su integración en el derecho al medio ambiente ${ }^{33}$. La

\footnotetext{
${ }^{31}$ EZEIZABARRENA, X., "Luces y sombras del derecho a un medio ambiente adecuado", Ongawa, Derecho al Agua y al Medio Ambiente sano para una vida digna, Ingeniería para el Desarrollo Humano y Fundación IPADE, Madrid, 2012, p. 24.

${ }^{32}$ La SCSJN de 2 de diciembre de 2014, K.42.XLIX, "Kersich, Juan Gabriel y otros c/ Aguas Bonaerenses y otros s/ amparo", resuelve el recurso extraordinario federal interpuesto por Aguas Bonaerenses S.A. (ABSA) contra la Sentencia de la Suprema Corte de Justicia de la Provincia de Buenos Aires por la que se rechaza su recurso extraordinario local dirigido contra la decisión de la Cámara de Apelaciones en lo Contencioso-Administrativo de La Plata que había confirmado la decisión del juez de primera instancia de admitir la adhesión a la demanda, en condición de actores, de 2.641 vecinos y ordenar, en consecuencia, que ABSA produjera de modo individual un informe circunstanciado de cada uno de los afectados.

${ }^{33}$ Los vecinos de 9 de Julio, provincia de Buenos Aires, se constituyeron en 2010 en la asociación "Todos por el Agua" a fin de reclamar agua potable, ya que los niveles de arsénico y otros contaminantes superaban el límite de lo permitido por la OMS y el Código Alimentario Argentino.
} 
importancia de esta sentencia estriba en los pronunciamientos efectuados por la Corte Suprema respecto a cuestiones tales como el reconocimiento del derecho al agua como un derecho humano, su condición de componente del bien colectivo ambiente, o su carácter de derecho colectivo e interés difuso, por lo que queda sujeto, por tanto, al ejercicio del amparo colectivo.

\section{Antecedentes: planteamiento del conflicto $y$ desarrollo procesal de las actuaciones}

La causa "Kersich" parte de una acción de amparo colectivo promovida por un grupo de veinticinco vecinos de la ciudad de 9 de Julio, provincia de Buenos Aires, contra la mercantil Aguas Bonaerenses S.A. (ABSA) y contra la provincia de Buenos Aires. La acción se dirige frente a la primera en su condición de empresa suministradora del servicio de agua potable, con el fin de que la prestadora del servicio tome las medidas necesarias para bajar los niveles de arsénico registrados en dicha localidad. En segundo lugar, la acción se dirige frente a la provincia de Buenos Aires en su condición de titular del dominio acuífero - cuya preservación es responsabilidad de la empresa prestataria del servicio-, con fundamento en la obligación del estado local de conservar los recursos naturales según dispone la Constitución local. La pretensión de la actora - la adecuación de la calidad y potabilidad del agua — se funda en el hecho de que el agua suministrada por ABSA contiene niveles de arsénico superiores a los permitidos por la legislación vigente (el agua de red de 9 de Julio presenta niveles muy altos en arsénico que oscilan entre los $0,05 \mathrm{mg} / 1$ hasta $\operatorname{los} 0,18 \mathrm{mg} / \mathrm{l}$, siendo el valor guía de la OMS 0,01 $\mathrm{mg} / \mathrm{l})^{34}$.

La presente causa aparece definida por dos decisiones fundamentales: la adopción en primera instancia de la medida cautelar solicitada por los demandantes - conservada posteriormente por la CSJN en el fallo de 2 de diciembre de 2014-; y la admisión, por el juez de grado, de la adhesión de 2.641 vecinos como parte actora - y que finalmente

\footnotetext{
${ }^{34}$ Las pretensiones de la actora se pueden sintetizar en las siguientes: i) la realización, en el plazo de 180 días, de los trabajos y las tareas necesarios a fin de adecuar la calidad y potabilidad del agua de uso domiciliario, según los parámetros establecidos por la OMS en coincidencia con la norma del artículo 982 del Código Alimentario Argentino; y ii) la determinación por ABSA de un plazo de adecuación efectiva de un proyecto específico con plazos concretos de realización, así como su posterior implementación tanto por el Organismo de Control de Aguas de Buenos Aires como por las áreas competentes que determine el Ministerio de Infraestructura local. Cfr. SCSJN de 2 de diciembre de 2014, "Kersich", Consid. $1 .^{\circ}$.
} 
ha sido una de las causas que han motivado la estimación del recurso extraordinario federal interpuesto por ABSA-. En relación con la primera de las cuestiones, el juez de grado acordaría la adopción de la medida cautelar solicitada, admitiendo las peticiones que en este sentido fueron formuladas por los actores. En consecuencia, se ordenó a ABSA el suministro individual a cada demandante, en su domicilio, y a las entidades educativas y asistenciales involucradas de agua potable —en bidones - adecuada a las disposiciones del artículo 982 del Código Alimentario Nacional ${ }^{35}$. El suministro se haría en la cantidad necesaria para satisfacer las necesidades básicas de consumo, higiene personal y limpieza de manos y alimentos y cocción de estos en una ración no menor a 200 litros por mes. Además, dispuso la prohibición del consumo de agua de la red domiciliaria provista por la demandada en los referidos establecimientos educativos y asistenciales y ordenó a ABSA la realización mensual de un análisis del agua distribuida al menos en diez domicilios del partido de 9 de Julio, debiendo publicar los resultados en los recibos de pago del servicio ${ }^{36}$. Asimismo, y respecto a la segunda de las cuestiones apuntadas, el juez de grado aceptaría la posterior adhesión de 2.641 personas en condición de nuevos actores, haciendo extensiva a todos ellos la medida cautelar adoptada. Ordenando a la demandada, con relación a todos y cada uno de ellos, acompañar un informe circunstanciado de rigor en el plazo de diez días ${ }^{37}$.

Frente a la resolución del juzgador de primera instancia, ABSA interpuso recurso de apelación ante la Cámara de Apelaciones en lo Contencioso-Administrativo de La Plata, solicitando la revocación de la medida cautelar. El fundamento de su recurso se apoya en tres ideas principales: i) la vulneración de su derecho de defensa, presente la dificultad que conlleva informar de forma detallada, y en el plazo de diez días, sobre la calidad de agua que suministra a cada uno de los reclamantes; ii) lo innecesario de que cada uno de los integrantes del colectivo afectado tuviera que personarse individualmente en la causa; la presencia de un colectivo constituido por los vecinos

\footnotetext{
${ }^{35}$ El Código Alimentario Argentino, Ley 18.284, de 18 de julio de 1969, es un reglamento técnico en permanente actualización que establece disposiciones higiénico-sanitarias, bromatológicas y de identificación comercial que deben cumplir las personas físicas o jurídicas, los establecimientos y los productos que se enmarcan en su órbita. Esta normativa tiene como objetivo primordial la protección de la salud de la población. El artículo 982 se destina a la definición de "Agua potable de suministro público" y "Agua potable de uso domiciliario", así como a regular las condiciones que estas deben reunir.

${ }^{36}$ Cfr. SCSJN de 2 de diciembre de 2014, "Kersich", Consid. 1. ${ }^{\circ}$.

${ }^{37}$ Ibídem, Consid. $2 .^{\circ}$, in fine. Es importante señalar aquí que el juzgador a quo aclaró expresamente que este lapso de tiempo podía ser ampliado a petición de la demandada teniendo en cuenta la cantidad de presentaciones efectuadas.
} 
promotores iniciales de la acción debió ser considerada suficiente para reemplazar virtualmente la actuación de los demás interesados; y iii) la existencia de un acuerdo extrajudicial en fase de ejecución alcanzado por la demandada y dos de los actores originales (Kersich y Crespo, presidente y vicepresidente de la Asociación Todos por el Agua), el Defensor del Pueblo de la Provincia de Buenos Aires, el ministro de Salud y la ministra de Infraestructura del estado local $^{38}$.

La Cámara de Apelaciones en lo Contencioso-Administrativo de La Plata desestimó las pretensiones de ABSA y confirmó el fallo apelado. Entre las consideraciones efectuadas, destacan el interés legítimo y suficiente de los actores y adheridos para promover la acción de amparo; la inexistencia de vulneración del derecho de defensa de la recurrente; o el reconocimiento implícito del daño causado que lleva a cabo la demandada a través del acuerdo extrajudicial alegado ${ }^{39}$. Por último, la Cámara de Apelaciones recurrió al principio precautorio para ponderar que, a partir del suministro de agua por debajo de los parámetros legales de calidad, se hallaban comprometidas las condiciones de salud de la población ${ }^{40}$. En función de ello, sostuvo que se encontraban reunidos los requisitos de verosimilitud del derecho y de peligro en la demora y que, por lo tanto, correspondía mantener la medida cautelar ${ }^{41}$.

No conforme con el fallo, ABSA continuó su peregrinaje judicial. Frente a la decisión de la Corte de Apelaciones se interpuso un recurso de inaplicabilidad de ley que, declarado inadmisible, dio lugar a un recurso de queja que la SCBA desestimó dejando

\footnotetext{
${ }^{38}$ Una solución del conflicto que pasaría por la construcción de una obra de infraestructura para adecuar el contenido de arsénico, habiéndose ejecutado ya 1.000 metros de cañerías de impulsión. ABSA solicitaría, junto con la revocación de la cautelar, que el referido acuerdo extrajudicial fuera homologado. Cfr. SCSJN de 2 de diciembre de 2014, "Kersich", Consid. 3. .

${ }^{39}$ La decisión de la Cámara de Apelaciones se fundamenta en las siguientes consideraciones: i) se tiene en cuenta que la recurrente no desconocía el interés legítimo de los actores y adherentes con relación al objeto de la pretensión que por su carácter no resulta susceptible de aprehensión individual; ii) los adherentes, en su condición de vecinos de la localidad afectada, ostentan un interés jurídico suficiente para considerarlos legitimados con el objeto de promover la acción de amparo; iii) no existe vulneración del derecho de defensa de la demandada -invocando la dificultad de responder el informe circunstanciado en el plazo de ley_-, presente que el juzgador concedió una ampliación del plazo para el caso de ser solicitada; y iv) en la medida en que ABSA no niega la existencia de elevados niveles de arsénico en el agua suministrada, reconociendo, además, haber llegado a un acuerdo extrajudicial por el que se comprometía a realizar obras para mejorar la calidad del agua y entregarla a los afectados en bidones sellados, existe por la recurrente un reconocimiento implícito de la conducta demandada. Vid. SCSJN de 2 de diciembre de 2014, "Kersich", Consid. 4. .

${ }^{40}$ De acuerdo con el principio precautorio, cuando haya peligro de daño grave o irreversible, la ausencia de información o certeza científica no debe utilizarse como razón para postergar la adopción de medidas eficaces, en función de los costos, para impedir la degradación del medio ambiente (art. 4, Ley 25.675 General del Ambiente - LGA-).

${ }^{41}$ SCSJN de 2 de diciembre de 2014, "Kersich", Consid. 4..
} 
firme lo resuelto. Finalmente, frente a esta última denegación, la recurrente plantea un recurso extraordinario federal cuya negativa daría lugar a la cuestión planteada ante la CSJN, finalizada por el fallo de 2 de diciembre de 2014 aquí analizado ${ }^{42}$.

Las cuestiones que fundamentan la posición de ABSA ante la Corte no son distintas de las ya examinadas. Se centra de forma principal en la adhesión de 2.641 nuevos actores y en las consecuencias que se derivan de esta. En primer lugar, señala que esta adhesión “desnaturaliza el funcionamiento del proceso colectivo, así como las características sumarísimas del juicio de amparo, provocando una grave violación al debido proceso"43. A juicio de la demandada, la presencia de un colectivo que actúa en "virtual representación del resto de interesados" debió considerarse "suficiente" para reemplazar la actuación personal de estos, máxime cuando se trata de un proceso sumarísimo de amparo colectivo en el que la intervención voluntaria de terceros se encuentra por principio excluida ${ }^{44}$. ABSA defiende que la incorporación a la causa de tantos litigantes como afectados, a los que hacerles extensiva la medida cautelar, vulnera lo preceptuado en los artículos 18 y $43 \mathrm{CN}$, así como en el artículo 33 de la Ley 25.675, General del Ambiente (LGA). De este modo, la Suprema Corte Provincial habría desconocido la función representativa del juicio colectivo y los efectos expansivos que este proceso puede llegar eventualmente a generar a su respecto ${ }^{45}$. Junto con lo anterior, la innecesaria intervención de 2.641 nuevos actores supera una razonable posibilidad de respuesta por su parte. Se produce una vulneración del derecho a la defensa por la imposibilidad tanto de controlar todas las condiciones de admisibilidad de los nuevos litigantes como de dar debido cumplimiento a las exigencias de ese informe detallado.

\footnotetext{
${ }^{42}$ Tal y como reconoce la CJSN, "el recurso extraordinario del art. 14 de la Ley 48, solo ha sido creado a objeto de asegurar la supremacía de la $\mathrm{CN}$, los tratados y leyes del Congreso, consagrada por el art. 31 de la primera, siendo privativa de los tribunales de cada Provincia, la interpretación de las instituciones locales que ellas mismas se han dado para su propio régimen y gobierno". Solo podrá deducirse ante la Corte Suprema el recurso extraordinario cuando en un pleito se haya planteado alguna de las cuestiones de carácter federal enumeradas en los tres incisos del recordado artículo 14 y concurran las demás condiciones que allí se mencionan. Cfr. CORTE SUPREMA DE JUSTICIA DE LA NACIÓN, Recurso extraordinario y recurso de queja: Parte I, CSJN, Buenos Aires, 2011, p. 3.

${ }^{43}$ SCSJN de 2 de diciembre de 2014, "Kersich", Consid. 6. ${ }^{\circ}$

${ }^{44}$ Ibídem.

${ }^{45}$ Tales efectos se desprenden de lo previsto en los artículos 43 CN y 33 LGA.
} 


\section{Doctrina de la Corte Suprema de Justicia de la Nación}

En la causa pueden diferenciarse dos cuestiones principales: por una parte, la cuestión atinente a la protección que en el ordenamiento nacional e internacional se brinda al acceso al agua potable - cuyo examen ha sido efectuado supra-; y, por otra, la naturaleza colectiva del derecho al agua y el tipo de proceso más eficiente para hacerlo efectivo.

La CSJN reconoce de forma expresa que la acción promovida por los demandantes es una acción colectiva. Como señala el Alto Tribunal, esta acción "procura la tutela de un derecho de incidencia colectiva referido a uno de los componentes del bien colectivo ambiente: el agua potable"46. De ahí que la pretensión de la actora —el suministro de agua potable en condiciones de salud - no sea susceptible de apropiación individual sino colectiva ${ }^{47}$. Debe tenerse en cuenta que, al tratarse de derechos fundamentales como el derecho a un medio ambiente sano o a la salud-, los jueces deben buscar soluciones procesales que utilicen las vías más eficaces para hacer efectivo el derecho de que se trate. La causa "Kersich", encarna esa tutela judicial urgente "en la medida que está en juego el derecho humano de acceso al agua potable, la salud y la vida de una gran cantidad de personas y al mismo tiempo existe una demora de la demandada en la solución definitiva de esta situación" ${ }^{48}$. Tratándose de un caso ambiental, el ordenamiento jurídico argentino otorga a los jueces amplias facultades en cuanto a la protección del ambiente. Como reconoce la CSJN, estos "pueden ordenar el curso del proceso, e incluso darle trámite ordinario a un amparo o bien dividir las pretensiones a fin de lograr una efectiva y rápida satisfacción en materia de prevención” ${ }^{49}$. Si bien, como se ha visto en precedentes jurisprudenciales, el límite de estas facultades viene

\footnotetext{
${ }^{46}$ Cfr. SCSJN de 2 de diciembre de 2014, "Kersich", Consid. 8..

${ }^{47}$ Como se adelantó, la parte actora persigue que la provisión domiciliaria de agua en red en la localidad de 9 de Julio se lleve a cabo cumpliendo con las características físicas y microbiológicas — contenido de arsénico, nitratos, flúor y sólidos disueltos - fijadas en los estándares del anexo A de la Ley local 11.820 y el artículo 982 del Código Alimentario Argentino. Cfr. SCSJN de 2 de diciembre de 2014, "Kersich", Consid. 8. ${ }^{\circ}$.

${ }^{48}$ Ibídem, Consid. 10..

${ }^{49}$ Cfr. SCSJN de 2 de diciembre de 2014, "Kersich", Consid. 10. ${ }^{\circ}$, in fine. En este sentido, y por los paralelismos de la acción ejercitada, vid. SCSJN de 8 de julio de 2008, fallos 331:1622, "Mendoza, Beatriz S. y otros v. Estado Nacional y otros s/daños y perjuicios (daños derivados de la contaminación ambiental del Río Matanza Riachuelo)”.
} 
dado por el respeto al debido proceso, de forma que los juzgadores no pueden alterar el objeto de la pretensión ${ }^{50}$.

La contaminación por arsénico en el agua suministrada en toda la localidad no es un problema de cada uno de los habitantes, sino que es un problema comunitario que, para su mejor solución, debe ser tratado en un proceso colectivo. Por lo tanto, la causa debió ceñirse desde el principio a las reglas procesales del amparo colectivo previstas en el artículo $43 \mathrm{CN}$. Sin embargo, y pese a que el juez de primera instancia calificó la causa como amparo colectivo, este hecho fue ignorado, recurriéndose en la tramitación a reglas procesales incompatibles con este tipo de proceso, "soslayando las consecuencias negativas que tal temperamento ocasionaría en el normal trámite de la causa"51. El Alto Tribunal reconoce el error de las anteriores instancias judiciales y la vulneración del derecho de defensa de ABSA "no solo por la carga que se le impusiera, sino también por el cambio sorpresivo de reglas" $" 52$.

En este tipo de procedimiento, como en todos, debe primar la protección de la seguridad jurídica y la buena fe. Corresponde al Tribunal, como director del proceso, tutelar que las partes tengan un conocimiento claro y meridiano de las reglas procesales a efectos de proteger el ejercicio de derechos constitucionales como el derecho de defensa. Por lo tanto, en el caso que nos ocupa, los jueces provinciales no debieron integrar, de forma sorpresiva, un número exorbitante de nuevos actores al amparo colectivo ambiental. Como reconoce la Corte, "se debieron arbitrar los medios procesales necesarios que, garantizando adecuadamente la defensa en juicio del demandado, permitieran que las decisiones adoptadas en el marco del presente proceso alcancen a la totalidad del colectivo involucrado" ${ }^{53}$. Por lo tanto, al permitir la adhesión de los 2.641 nuevos actores se produce una efectiva desnaturalización del amparo colectivo, el cual, caracterizado por su función representativa y sus efectos expansivos, no precisa la personación de todos los afectados en condición de nuevos actores. La CSJN reconoce que este cambio sorpresivo de las reglas, que se aparta de la buena fe, pone en peligro el

\footnotetext{
${ }^{50}$ SCSJN de 20 de junio de 2006, fallos 329:2316, "Mendoza, Beatriz S. y otros v. Estado Nacional y otros s/daños y perjuicios (daños derivados de la contaminación ambiental del Río Matanza Riachuelo)". Vid. PÉREZ DE LOS HERNÁNDEZ, "Leading..." cit.

${ }^{51}$ Cfr. SCSJN de 2 de diciembre de 2014, causa "Kersich”, Consid. 9..

${ }^{52}$ Ibídem, Consid. 11. ${ }^{\circ}$.

${ }^{53}$ Ibídem, in fine.
} 
derecho de defensa de la recurrente ex artículo 15 de la Ley $48^{54}$. Y en este sentido, el Alto Tribunal puso de manifiesto que "el examen de los recaudos de admisibilidad de la instancia recursiva local, se llevó a cabo con un injustificado rigor formal que concluyó con la arbitraria cancelación de la vía revisora de que se trata, omitiendo con este modo de resolver el tratamiento de una cuestión federal oportunamente articulada, con la consecuente frustración de los derechos comprometidos en dicho planteo tal como el derecho humano al agua" 55 .

Todo lo anterior justifica que la CSJN declare procedente el recurso extraordinario, con la consecuente invalidación del pronunciamiento, a fin de que la pretensión formulada sea nuevamente considerada y decidida mediante un fallo constitucionalmente sostenible y teniendo en cuenta su carácter de urgente. Si bien, con un laudable criterio, el Alto Tribunal toma la decisión de conservar, hasta que se cumpla con lo ordenado, la medida cautelar adoptada en primera instancia. El basamento de su decisión estriba en la importancia fundamental del derecho que se protege, el derecho humano al agua, para cuya protección resultan elementales los principios de prevención y, aun en la duda técnica, el principio precautorio.

\section{CONCLUSIONES}

Primera. Los problemas medioambientales, en especial la contaminación, tienen una fuerte influencia sobre la implementación de todos los derechos humanos, resultando especialmente crítico su impacto sobre el derecho humano al agua y al saneamiento. La interrelación existente entre el agua y el medio ambiente, reconocida de forma permanente por los encuentros internacionales de finales del siglo XX, fundamenta dos de los grandes retos del siglo XXI: por una parte, la necesidad de garantizar el acceso universal al agua potable y el saneamiento, $\mathrm{y}$, por otra, la obligada protección y conservación del medio ambiente.

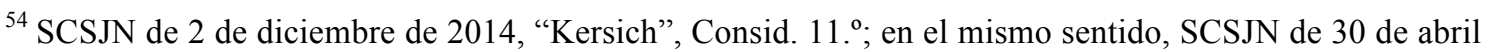
de 2013, fallo CSJ 471/2011 (47-T), “TTT., María Luisa c. Obra Social del Personal auxiliar de casas particulares".

${ }^{55}$ SCSJN de 2 de diciembre de 2014, "Kersich", Consid. 13. . El Alto Tribunal se remite a las SCSJ, de 10 de diciembre de 2013, fallos 232/2010 (46-L), "L., S. R. y otra c/ Instituto de Seguridad Social de la Provincia - subsidio de salud s/ amparo" y SCSJ, de 7 de octubre de 2014, 811/2008 (44-P), "Pilquiman, Crecencio c/ Instituto Autárquico de Colonización y Fomento Rural”.
} 
Segunda. Los derechos ambientales han tenido un reconocimiento incuestionable a todos los niveles normativos: internacional, mediante los tratados internacionales; nacional, por mor de la cláusula ambiental ex artículo $41 \mathrm{CN}$; y también a nivel provincial e incluso local. Por su parte, el reconocimiento del derecho humano al agua es hoy por hoy una realidad incontestable. Se encuentra indiscutiblemente implícito en el derecho a la vida y es fundamento ontológico del resto de derechos que se puedan reconocer, fundamentales o no. Además, encuentra un acceso directo a través del artículo $41 \mathrm{CN}$, por el que se consagra el derecho a un medio ambiente sano, equilibrado y apto para el desarrollo, integrando así los derechos humanos de tercera generación.

Tercera. Los derechos de tercera generación se caracterizan por su sujeto colectivo - la humanidad en su conjunto - y por su objeto — los bienes jurídicos que pertenecen al género humano, tanto a las generaciones presentes como a las futuras-. La incorporación de estos derechos al ordenamiento jurídico argentino llega de la mano de la reforma constitucional de 1994, que incorpora el reconocimiento de nuevos derechos y garantías para los ciudadanos, junto con el otorgamiento de rango constitucional a los tratados internacionales de derechos humanos (ex art. 75 inc. $22 \mathrm{CN}$ ). La CN reconoce los derechos de incidencia colectiva en los artículos 41 y $42 \mathrm{CN}$, entre los que se identifican los derechos ambientales según los términos del propio artículo $43 \mathrm{CN}$. Lo mismo cabe afirmar respecto del derecho al agua, pues, como señala la propia CSJN, "en el campo de los derechos de incidencia colectiva, es fundamental la protección del agua para que la naturaleza mantenga su funcionamiento como sistema y su capacidad de resiliencia" (SCSJN de 2 de diciembre de 2014, "Kersich", Consid. 12. ${ }^{\circ}$ ).

Cuarta. La importancia de estos intereses difusos se plasma también a nivel procesal, configurando un procedimiento judicial de características singulares. Para su defensa, la reforma constitucional de 1994 introdujo el amparo colectivo. Esta figura se caracteriza por proteger los derechos de incidencia colectiva; por el hecho de que los sujetos legitimados para promover el amparo no necesitan ser titulares de un derecho subjetivo, siendo suficiente con encontrarse vinculados al colectivo sobre el que incide la vulneración; y por el hecho de que la sentencia que se dicte, en caso de declarar procedente el reclamo, tiene efectos erga omnes, estableciendo una conducta de carácter general más allá de las partes del proceso. 
Quinta. En los procedimientos judiciales cuyo objeto son derechos fundamentales, los jueces deben buscar soluciones procesales que utilicen las vías más eficaces para hacer efectivo el derecho de que se trate. En concreto, tratándose de un caso ambiental, el ordenamiento jurídico argentino otorga a los jueces amplias facultades en cuanto a la protección del ambiente. Estos pueden ordenar el curso del proceso, e incluso darle trámite ordinario a un amparo o bien dividir las pretensiones a fin de lograr una efectiva y rápida satisfacción en materia de prevención. El límite de estas facultades viene dado por el respeto al debido proceso, de forma que los juzgadores no pueden alterar el objeto de la pretensión.

Sexta. Un ejemplo de todo lo anterior lo encontramos en la causa "Kersich, Juan Gabriel y otros c/ Aguas Bonaerenses y otros s/ amparo". Un pronunciamiento en el que la CSJN lleva a cabo un reconocimiento expreso del derecho humano al agua, de la condición del agua potable como un elemento del bien colectivo ambiente, y del amparo colectivo como la vía adecuada para la defensa de este interés difuso. Dentro de este último, reitera su función representativa y sus efectos expansivos, de forma que se torna innecesaria la personación de todos los afectados en condición de nuevos actores. $\mathrm{Si}$ bien, pese a dar cabida al recurso extraordinario presentado por la demandada, la Corte Suprema prioriza intereses y toma la decisión de conservar, hasta que se cumpla con lo ordenado, la medida cautelar adoptada en primera instancia. El basamento de su decisión estriba en la importancia fundamental del derecho que se protege, el derecho humano al agua, para cuya protección resultan elementales los principios de prevención y, aun en la duda técnica, del principio de precaución.

\section{BIBLIOGRAFÍA}

AGUILAR ROJAS, G. e IZA, A., (eds.), Derecho ambiental en Centro América, T. I, UICN, Gland, Suiza, 2009.

ÁlVAREZ, N. R. (2006, 8 de septiembre). Derechos de Incidencia Colectiva y Amparo. Recuperado el 22 de septiembre de 2015, de: $<$ http://www.poderyderecho.blogspot.com.ar/2006/09/derechos-de-incidencia-colectivay.html>

ANDORNO, L. O, "Aspectos constitucionales de la protección del medio ambiente", JA, T. IV, 1998. 
ANTÚNEZ SÁNCHEZ, A. y BRUZÓN VILTRES, C., "Una mirada a los Derechos Humanos desde la óptica del Derecho Ambiental Internacional. Resultados de la primera década del siglo XXI", Revista de Derecho Ambiental, núm. 34, Buenos Aires, 2013.

CAVALLI, A., Derecho de aguas, Documento de trabajo núm. 168, Departamento de Investigaciones de la Universidad de Belgrano, Buenos Aires, 2007.

CORTE SUPREMA DE JUSTICIA DE LA NACIÓN, Recurso extraordinario y recurso de queja: Parte I, CSJN, Buenos Aires, 2011.

EZEIZABARRENA, X., "La tutela jurídica del medio ambiente”, Ruiz Díaz, J. A. y Ramos Castellanos, P. (ed.), El hombre y el medio ambiente, Aquilafuente, Salamanca, 2010.

— "Luces y sombras del derecho a un medio ambiente adecuado", Ongawa, Derecho al Agua y al Medio Ambiente sano para una vida digna, Ingeniería para el Desarrollo Humano y Fundación IPADE, Madrid, 2012.

GAMBIER, B. y LAGO, D. H., "El medio ambiente y su reciente recepción constitucional", ED, T. 163, 1995.

GÓMEZ GARCÍA, J. A., "Los llamados derechos humanos de tercera generación”, Muinelo Cobo, J. C. y Muñoz de Baena Simón, J. L. (coords.), Filosofía del Derecho, UNED, Madrid, 2014.

HITTERS, J. C. y FAPPIANO, O. L., Derecho internacional de los Derechos Humanos, t. II, vol. 2, Ediar, Buenos Aires, 2007.

IZA, A. y ROVERE, M. B., Gobernanza del agua en América del Sur: dimensión ambiental, UICN, Gland, Suiza, y Cambridge, Reino Unido, 2006.

LOPERENA ROTA, D., El derecho al medio ambiente adecuado, Civitas, Madrid, 1998.

MARTÍN MATEO, R., El hombre, una especie en peligro, Campomanes, Madrid, 1993.

MARTÍN, L. y PINTO, M., “Origen, evolución y estado actual del derecho al agua en América Latina", revista Bioderecho.es, vol. 1, núm. 1, 2014. 
— "El Derecho Humano al Agua. Evolución, protección y efectividad", HYDRIA, año 8, núm. 39, febrero de 2012.

MARTÍN, L., PINTO, M. y TORCHIA, N., El Derecho Humano al agua. Particularidades de su reconocimiento, evolución y ejercicio, Abeledo Perrot, Buenos Aires, 2008.

MARTÍN, L., PINTO, M., TORCHIA, N., GONZÁLEZ DEL SOLAR, N. y RUIZ FRITES, S., "Configuración del derecho humano al agua: del uso común al derecho humanos. Particularidades de su integración y expansión conceptual”, Embid Irujo A., (dir.), El derecho al agua, Thomson Aranzadi, Cizur Menor, Navarra, 2006.

OFICINA DEL ALTO COMISIONADO DE LAS NACIONES UNIDAS PARA LOS DERECHOS HUMANOS DE GINEBRA, "El derecho al agua", Folleto informativo núm. 35.

ORAA, J. y GÓMEZ ISA, F., La Declaración Universal de Derechos Humanos, Universidad de Deusto, Bilbao, 2009.

PÉREZ DE LOS COBOS HERNÁNDEZ, E., "Leading case ambiental: la causa "Mendoza" y el reconocimiento de los derechos de tercera generación", Revista Aranzadi de Derecho Ambiental, núm. 30, 2015.

- La incorporación de la variable ambiental a los conflictos competenciales en materia de aguas en España y en Argentina, tesis doctoral, Universidad de Murcia, España, 2014.

- "La cuenca Matanza-Riachuelo, una deuda ambiental histórica", revista Bioderecho.es, vol. 1, núm. 1, 2014.

QUiRogA LAVIÉ, H., BENEDETTI, M. A. y CENICACELAYA, M., Derecho Constitucional Argentino, T. I., Rubinzal-Culzoni, Buenos Aires, 2001.

SMETS, H., El derecho al agua en las legislaciones nacionales, Universidad de Rosario, Bogotá, 2006.

WALSH, J. R., "El medio ambiente en la nueva Constitución argentina”, $L L$, Supl. de Derecho Ambiental, núm. 1, 1994. 